\title{
The role of DYRK1A in neurodegenerative diseases
}

\author{
Jerzy Wegiel ${ }^{1}$, Cheng-Xin Gong ${ }^{2}$, and Yu-Wen Hwang ${ }^{3}$ \\ ${ }^{1}$ Department of Developmental Neurobiology, New York State Institute for Basic Research in \\ Developmental Disabilities, Staten Island, New York, USA \\ 2 Department of Neurochemistry, New York State Institute for Basic Research in Developmental \\ Disabilities, Staten Island, New York, USA \\ ${ }^{3}$ Department of Molecular Biology, New York State Institute for Basic Research in Developmental \\ Disabilities, Staten Island, New York, USA
}

\section{Abstract}

Recent studies indicate that the dual-specificity tyrosine phosphorylated-regulated kinase $1 \mathrm{~A}$ (DYRK1A) gene, which is located on chromosome 21q22.2 and is overexpressed in Down syndrome (DS), may play a significant role in developmental brain defects and in early-onset neurodegeneration, neuronal loss and dementia in DS. Identification of hundreds of genes deregulated by DYRK1A overexpression, and numerous cytosolic, cytoskeletal and nuclear proteins, including transcription factors, phosphorylated by DYRK1A, indicates that DYRK1A overexpression is central for deregulation of multiple pathways in the developing and aging DS brain, with structural and functional alterations including mental retardation and dementia. DYRK1A overexpression in DS brains may contribute to early-onset neurofibrillary degeneration directly through hyperphosphorylation of tau and indirectly through phosphorylation of alternative splicing factor (ASF), leading to an imbalance between 3R-tau and 4R-tau. The severalfold increases in the number of DYRK1A-positive and 3R-tau-positive neurofibrillary tangles in DS support this hypothesis. Moreover, the enhanced phosphorylation of amyloid precursor protein (APP) by overexpressed DYRK1A facilitates amyloidogenic APP cleavage elevating A $\beta 40$ and 42 levels, and leading to brain $\beta$-amyloidosis. Therefore, inhibiting Dyrk1A activity in DS may serve to counteract the phenotypic effects of its overexpression and is a potential method of treatment of developmental defects and prevention of age-associated neurodegeneration, including Alzheimer type pathology.

\section{Keywords}

DYRK1A; neurodegeneration; tau phosphorylation; amyloid- $\beta$ peptide; alternative splicing factor; $\alpha$-synuclein; Down syndrome; Alzheimer disease

\section{Introduction}

The minibrain $(m n b)$ gene mutation has been identified as a cause of abnormal brain development, of deficits of postembryonic neurogenesis and of reduced numbers of neurons in Drosophila. In addition to the proliferative deficits, the $m n b$ mutation causes neurodegeneration, which is considered a consequence of the lack of sufficient cell-cell

Correspondence: Jerzy Wegiel, Ph.D., New York State Institute for Basic Research in Developmental Disabilities, 1050 Forest Hill Road, Staten Island, New York, 10314, USA, Tel: 718 494-5231, Fax: 718 494-4856, jerzy.wegiel@omr.state.ny.us.

Authors declare no conflict of interest. 
contacts required for the maintenance of Drosophila optic lobe neurons [1]. The broad spectrum of abnormalities caused by the mnb gene mutation in Drosophila suggests multiple biological functions of the kinase encoded by this gene.

The human orthologue of the Drosophila mnb gene, named DYRK1A (dual-specificity tyrosine phosphorylation-regulated kinase 1A) [2], is mapped to human chromosome 21q22.2 [3], a region of the chromosome implicated in Down syndrome (DS). DS, caused by partial or complete trisomy of chromosome 21 , is the most common chromosomal disorder associated with abnormal brain development, including reduced size of the brain and number of neurons, smaller neurons, and reduced dendritic tree, contributing to mental retardation [4]. Trisomy of chromosome 21 also results in early aging, which is manifested in the third decade of life, and early onset of Alzheimer-type pathology, such as neurofibrillary degeneration, $\beta$-amyloidosis and neuronal loss, affecting almost all DS subjects who are older than 40 years of age $[5,6]$.

DYRK1A has multiple biological functions that are reflected in its interactions with numerous cytoskeletal, synaptic and nuclear proteins, including transcription and splicing factors [7,8]. The accompanying review by Tejedor and Hämmerle [9] characterizes DYRK1A as regulator of a broad spectrum of neurodevelopmental mechanisms. The identification of 239 genes that are deregulated by overexpressed DYRK1A through the REST/NRSF chromatin remodeling complex suggests a central role of this kinase in brain pathology [10]. Expression of DYRK1A in neurons during fetal and postnatal life, as well as in neurons of adults and aged subjects, suggests that regulated DYRK1A expression is a component of neuron development, maturation and aging [11].

DYRK1A-/- mice embryos present significant growth delay, with body size reduced by $25 \%$ to $50 \%$, and die between E10.5 and E13.5. Reduced postnatal viability, with a loss of $29 \%$ of DYRK1 A+/- mice during the first 3 days of life, reduced body weight, brain size and total number of neurons, indicate that DYRK1A plays a vital role in cellular mechanisms that determine body and brain growth and development [12].

Recent studies of DS brains indicate that overexpression of DYRK1A, due to the third copy of DYRK1A, not only causes developmental defects with life-long structural and functional consequences, but also contributes to neurodegeneration, neuronal death and loss of function. The mechanisms and potential therapeutic effects of selective inhibition of overexpressed DYRK1A are reviewed by Becker and Sippl [13].

\section{DYRK1A distribution}

The pattern of DYRK1A distribution in human brain is brain region-, cell type-, and subcellular compartment-specific. In control brains, the level of DYRK1A is almost identical in the frontal, temporal and occipital cortices (17-18 ng/mg of total proteins). In all examined subregions of brains of DS subjects, the level of DYRK1A is higher than in control brains, but with an increase that varies topographically from $25 \mathrm{ng} / \mathrm{mg}$ in the frontal cortex, $21 \mathrm{ng} / \mathrm{mg}$ in the temporal cortex, $20 \mathrm{ng} / \mathrm{mg}$ in the occipital cortex, to only $15 \mathrm{ng} / \mathrm{mg}$ in the cerebellar cortex [14]. Striking brain structure-specific and neuron type-specific differences in the distribution of DYRK1A detected by immunocytochemistry (Fig. 1) indicate that the role of DYRK1A in development, maturation, aging and degeneration may vary in different brain structures and with the types of neurons [11].

DYRK1A contains a bipartite nucleus targeting sequence [2], and the overexpressed exogenous DYRK1A has largely been found in the nucleus [15]. In contrast to the expected prevalence of endogenous DYRK1A in the nuclear fraction, in the human brain, only $12 \%$ of brain DYRK1A is detected in the nucleus; 78\% is associated with an insoluble 
cytoskeletal fraction, and $10 \%$ with a soluble cytoplasmic fraction [16]. A similar type of DYRK1A subcellular distribution was also observed in rat [17] and mouse [18] brains. The difference in phosphorylation of DYRK1A in cell compartments indicates that intracellular trafficking of DYRK1A may be regulated by DYRK1A phosphorylation [16]. This pattern of subcellular distribution is in agreement with immunocytochemical staining of DYRK1A in neurons (Fig. 1) and is also consistent with reports demonstrating that DYRK1A phosphorylates numerous substrates in the cytosol, cytoskeleton, synapses and nucleus [8]. Therefore, the overexpression of DYRK1A in DS and other disorders may produce brain region-, cell type-, and cell compartment-specific changes, altering brain development, maturation and susceptibility to neurodegeneration.

\section{Abnormal expression of DYRK1A in neurodegenerative diseases}

Increased DYRK1A immunoreactivity has been reported in the cytoplasm and nuclei of scattered neurons of the entorhinal cortex, hippocampus and neocortex in neurodegenerative diseases associated with tau phosphorylation, including AD, DS and Pick disease [19]. The percentage of neurons with increased DYRK1A immunoreactivity showed significant differences across individuals and brain structures. The percentage of DYRK1A-positive nuclei in the frontal cortex was only $0.5 \%$ in controls, $10 \%$ in AD and 5\% in Pick disease. The percentage of DYRK1A-positive nuclei in the dentate gyrus granule layer, which was determined to be $0.5 \%$ in control subjects and AD, increases to $60 \%$ in Pick disease [19]. Significant changes in DYRK1A expression during development and due to disease indicate that structure-specific, age-associated and disease-associated factors modify the amount and distribution of DYRK1A. Several studies suggest that the cytoplasmic and nuclear level of DYRK1A is cell type-specific $[11,19,20]$ and that local levels of overexpressed DYRK1A might be a factor co-determining cell susceptibility to age/AD-associated neurofibrillary degeneration in DS [20-22].

\section{The role of DYRK1A in tauopathies}

An initial in vitro study revealed that DYRK1A phosphorylates human microtubuleassociated protein tau at Thr-212 [23], but the list of phosphorylation sites has since been expanded to 11, including Thr-181, Ser-199, Ser-202, Thr-205, Thr-212, Thr-217, Thr-231, Ser-396, Ser-400, Ser-404 and Ser-422 [21]. The majority of the DYRK1A-mediated phosphorylation sites of tau are significantly hyperphosphorylated in the DS brain. Genedosage-related increases in DYRK1A levels in DS appear to be the major factor distinguishing the pattern and consequences of tau protein hyperphosphorylation in DS and in sporadic AD [21]. DYRK1A-induced phosphorylation of tau reduces the biological activity of tau protein and promotes tau self-aggregation and fibrillization. The abnormal tau phosphorylation causes the loss of tau biological function, resulting in reduced activity to stimulate microtubule assembly [21,24]. Moreover, hyperphosphorylated tau gains pathological properties, resulting in sequestration of normal tau and other microtubuleassociated proteins. Self-aggregation of tau leads to paired helical filament formation, neurofibrillary degeneration and neuron death. DYRK-mediated tau phosphorylation primes further tau phosphorylation at Ser-199, Ser-202, Thr-205 and Ser-208 with GSK-3 $\beta$ [21,23]. Phosphorylation of tau by both DYRK1A and GSK-3 $\beta$ enhances both self-aggregation and fibril formation in vitro [21,24]. The link between overexpression of DYRK1A and tau phosphorylation is also detected in Ts65Dn mice, a mouse model of DS trisomy that carries an additional copy of the distal segment of murine chromosome 16, including the DYRKIA gene [25]. These mice reveal 1.5-fold greater expression and activity of DYRK1A, and increased tau protein phosphorylation [21]. 
The direct evidence of the contribution of overexpressed DYRK1A to neurofibrillary degeneration in DS is a several-fold greater number of DYRK1A-positive NFTs in the brains of people with DS/AD than in the brains of people with sporadic AD (Fig. 2) [20]. DYRK1A phosphorylates tau protein at the sites that are phosphorylated in AD. In NFTs, tau protein is phosphorylated by several protein kinases, including GSK-3 $\beta$, cyclindependent kinase5 (CDK5), c-Jun N-terminal kinase (JNK), extracellular signal-regulated kinases1/2 (ERK1/2) and p38 mitogen-activated protein kinases at more than 30 phosphorylation sites [26-31]. Several kinases in their activated forms co-localize with NFTs in AD, including ERK2 [32], microtubule-affinity-regulating kinase [33], GSK-3 $\beta$ [34], CDK5 [35], Cdc2-related kinase [36] and casein kinase $1 \delta$ [37]. DYRK1A not only phosphorylates tau protein but also colocalizes with NFTs. The presence of DYRK1Apositive NFTs in all subjects with DS/AD but in only $60 \%$ of people diagnosed with sporadic AD suggests a link between DYRK1A overexpression in DS and neurofibrillary degeneration. The presence of DYRK1A-positive NFTs in all NFT-positive subjects with DS who are 38-51 years of age indicates that DYRK1A contributes to the early onset of neurofibrillary degeneration. The increase with age in the percentage of DYRK1A-positive NFTs up to $100 \%$ in some subjects from 58-67 years of age, reflects the increasing contribution of DYRK1A with age to the progression of neurofibrillary degeneration in DS subjects. However, in sporadic AD, the percentage of DYRK1A-positive NFTs does not change with age or disease duration. Striking differences in the detection of intracellular NFTs with antibody G-19 (Santa Cruz Biotech.) in the majority of NFTs, the reaction with antisera X1079 (Exalpha Biologicals) and 324446 (EMD4Bioscience) in only 10\% of G-19positive NFTs, and the lack of reaction of NFTs with antibody 7F3 indicate that epitopes detected with these antibodies against DYRK1A are masked in complexes of DYRK1A with tau and potentially with other proteins [20].

Neuropathological and molecular studies indicate that overexpressed nuclear DYRK1A contributes to modification of the alternative splicing of tau and neurofibrillary degeneration. DYRK1A phosphorylates the alternative splicing factor (ASF), mainly at Ser-227, Ser-234 and Ser-238. The phosphorylation of these three sites is neither catalyzed by the three other known ASF kinases (SRPK1, SRPK2, and Clk/Sty [22]) nor modulated by DNA topoisomerase I [38].

ASF binds to a polypurine enhancer of exonic splicing enhancer located at tau exon 10 (E10) and promotes the inclusion of E10 in the mRNA driving 4R-tau synthesis [39,40]. Phosphorylation regulates the trafficking and function of ASF. Phosphorylation of ASF by DYRK1A drives this factor to nuclear speckles, the site of storage of inactivated serine/ arginine-rich proteins including ASF. This mechanism prevents ASF from facilitating tau E10 inclusion and up-regulates the expression of 3R-tau [22]. Equal levels of 3R- and 4Rtau are critical for optimal neuron function [41]. The predominance of 3R-tau results in the tauopathy observed in Pick disease, whereas the predominance of 4R-tau causes tau pathology and neuronal loss in progressive supranuclear palsy and corticobasal degeneration [42]. Phosphorylation of ASF by overexpressed DYRK1A is considered the foundation for the approximately four-fold increase of 3R-tau in DS. The increase in the level of free 3Rtau available for abnormal hyperphosphorylation contributes to alterations of cell cytoskeleton and neurofibrillary degeneration in DS [22]. Immunohistochemically, severalfold more 3R-tau-positive NFTs are seen in DS brain than in AD brain (Fig. 2), further supporting the contribution of DYRK1A to neurofibrillary degeneration in DS.

Application of 2D-gel electrophoresis demonstrates that the pattern of ASF phosphorylation is different in subjects with DS/AD than in sporadic AD or control subjects. The direct evidence of the prevalence of 3R-tau in DS/AD is a several-fold increase in the number of 3R-tau-positive NFTs in the entorhinal cortex, hippocampus, amygdala and neocortex of 
DS/AD subjects in comparison to sporadic AD subjects. Differences between neuron-typespecific patterns of DYRK1A nuclear expression and the rather uniform distribution of ASF suggest that the elevated ratio of nuclear DYRK1A to ASF is a risk factor determining neuron-type susceptibility to neurofibrillary degeneration [43].

In DS, DYRK1A overexpression appears to be the cause of gene-dosage-dependent modifications of several mechanisms that contribute to the early onset of neurofibrillary degeneration, including DYRK1A phosphorylation of tau protein at 11 sites $[21,23,44]$; the DYRK1A-stimulated, several-fold increase in the rate of tau protein phosphorylation by GSK-3 $\beta$ [21,44]; the several-fold increase in the number of DYRK1A-positive NFTs in the brains of people with DS/AD [18]; phosphorylation of ASF, leading to alternative splicing of E10; and the several-fold greater number of 3R-tau-positive NFTs in the brains of people with DS/AD than in sporadic AD $[22,43]$.

Neurofibrillary degeneration is the leading cause of neuronal death and dementia in DS/AD and $\mathrm{AD}$. The multi-pathway involvement of DYRK1A in neurofibrillary degeneration indicates that therapeutic inhibition of overexpressed DYRK1A activity to control levels may delay the age of onset and inhibit the progression of neurodegeneration in DS.

\section{Contribution of overexpressed DYRK1A to amyloidosis- $\beta$ in DS}

A broad spectrum of developmental and age-associated changes in people with DS is considered a result of the overexpression of genes localized on chromosome 21 . The extra copy of the gene encoding APP located on chromosome 21 appears to be the main cause of the early onset of brain amyloidosis- $\beta$ in people with DS. Overexpression of APP has been associated with an increase in $A \beta 42$ levels in the brains of fetuses with trisomy of chromosome 21 [45], the development of diffuse $A \beta$-positive plaques in approximately $50 \%$ of individuals with DS younger than 30 years of age [46,47], Alzheimer-type pathology in the majority of DS subjects older than 40 years of age [47] and an elevated risk of ADassociated dementia [48,49].

Experimental studies suggest that overexpression of DYRK1A could be a primary risk factor contributing to the enhancement of both $\beta$-amyloidosis and neurofibrillary degeneration. Various kinases phosphorylate the APP cytosolic domain, including GSK-3 $\beta$ [50], Cdc2 kinase [51], CDK5 [52] and JNK3 [53]. Recent studies by Ryoo et al. [54] revealed that DYRK1A phosphorylates APP at Thr-668 in vitro and in mammalian cells. The increase of DYRK1A concentration is associated with increased APP phosphorylation at Thr-668 and colocalization of DYRK1A and APP in cytosol [54]. Elevated levels of phospho-APP are observed in AD, particularly in the hippocampus [55]. The phosphorylation of APP at Thr-668 may facilitate cleavage of APP by BACE1 [55] and $\gamma$ secretase $[55,56]$ and enhance the production of $A \beta$. Elevated $A \beta 40$ and $A \beta 42$ production by $160 \%$ and $17 \%$, respectively, detected in the hippocampus of DYRK1A transgenic mice, suggests that DYRK1A overexpression promotes APP cleavage and A $\beta$ production [54]. Accumulation of toxic, soluble $A \beta$ oligomers inhibits many critical neuronal activities, including long-term potentiation, leading to memory deficit. Recent studies strongly support the hypothesis that soluble $\mathrm{A} \beta$ oligomers contribute to dementia in $\mathrm{AD}$ [57]. Increased expression of DYRK1A mRNA in the hippocampus of $\mathrm{AD}$ patients and in vitro stimulation by $A \beta$ of DYRK1A mRNA expression in neuroblastoma cells [58] indicate that DYRK1A and $A \beta$ may positively feedback and accelerate $A \beta$ production.

In DS, three copies of the APP and DYRK1A genes result in increased APP and DYRK1A mRNAs $[59,60]$ and increased levels of DYRK1A and APP by 50\% and 55\%, respectively [54]. The increase of phospho-APP in DS brains by $82 \%$ and $23 \%$ after normalization to the levels of actin and APP, respectively, suggests that elevations of DYRK1A and APP may 
give rise to brain amyloidosis in DS through DYRK1A-mediated phosphorylation of APP [54]. Elevated $A \beta$ levels could subsequently increase expression of the DYRK1A gene and enhance hyperphosphorylation of tau $[21,44,54,58]$. These observations reveal a potential regulatory link between DYRK1A and APP proteolytic cleavage, enhanced levels of A $\beta$ upregulating DYRK1A mRNA expression, and the cascades of events associated with DYRK1A overexpression.

\section{The role of DYRK1A in a-synucleinopathies and other forms of neurodegeneration}

Several reports have indicated that DYRK1A can contribute to other forms of degeneration, including $\alpha$-synuclein aggregation and fibrillization in Lewy bodies (LBs), granulovacuolar degeneration (GVD) in the hippocampal pyramidal neurons, and neuronal and astrocyte degeneration with DYRK1A-positive corpora amylacea deposition in aging, AD and DS/AD and other diseases.

Dyrk1A phosphorylates $\alpha$-synuclein at Ser-87, enhances cytoplasmic aggregate formation and potentiates $\alpha$-synuclein pro-apoptotic effects [61]. $\alpha$-synuclein-positive LBs and neuritic processes frequently occur in DS brains with AD phenotypes [62]. DYRK1A phosphorylates and binds $\alpha$-synuclein [61] and SEPT4 [63], and complexes of these three proteins may contribute to the cytoplasmic aggregation/fibrillization observed in Parkinson disease (PD), Lewy body dementia and multiple-system atrophy [64,65]. SEPT4 has been detected in NFTs, neuropil threads and dystrophic neurites in amyloid plaques in AD [66]. Binding of DYRK1A to SEPT4 and the presence of SEPT4 and DYRK1A in NFTs and Lewy bodies suggest that the DYRK1A/SEPT4 tandem may play a significant role in both tauopathies and $\alpha$-synucleinopathies.

GVD is observed in neurons in the majority of normal aged subjects, and their number increases in persons with AD [67] and DS [68]. The granular component of vacuoles reacts with antibodies to tubulin [69], abnormally phosphorylated tau [70] and GSK-3 $\beta[34,35]$ as well as to ubiquitin [71]. The presence of DYRK1A immunoreactivity in granules in neurons with GVD detected with C-terminal antibodies (X1079 and 324446) and the lack of reactivity with antibodies against the N-terminus (7F3 and G-19) may indicate that only Nterminally truncated products of DYRK1A contribute to GVD or are selectively accumulated in these granules [20].

The strong immunoreactivity of the corpora amylacea with antibodies detecting the amino and carboxyl terminal portions of DYRK1A, including 7F3, G-19, X1079 and 324446, suggests that DYRK1A is involved in this common form of neuron and astrocyte degeneration and the early onset of these changes in DS [20]. Strong diffuse or granular immunoreactivity in the cytoplasm of almost all astrocytes in areas with massive astrocyte degeneration with corpora amylacea formation suggests the link between the cytoplasmic overexpression of DYRK1A and the risk of astrocyte degeneration in aging, DS and AD.

\section{Concluding remarks}

For decades, the molecular mechanisms of DS developmental abnormalities, mental retardation and early onset of Alzheimer's-type pathology remained elusive. Recent studies indicate that the overexpression of DYRK1A contributes to an early onset of neurofibrillary degeneration, amyloidosis- $\beta$, neuronal loss and dementia in DS (Fig. 3). The progress that has been made in the identification of overexpressed DYRK1A as a factor involved in a broad spectrum of molecular, functional and structural modifications underlying the DS phenotypes offers a rationale for the design of new preventive and therapeutic treatments of 
DS. One may hypothesize that the inhibition of excessive activity of DYRK1A may result in cytoplasmic and nuclear pathways of the prevention/delay of several forms of neurodegeneration. A few potent DYRK1A inhibitors have been described [12,72,73]. Among inhibitors, epigallocatechin 3-gallate (EGCG), the major polyphenolic flavonoid in tea, has recently emerged as a candidate for therapeutic or prophylactic applications. EGCG could rescue the synaptic plasticity deficiency of Ts65Dn mice [74]. EGCG and related catechins were also successfully applied to treat the learning deficits associated with DYRK1A transgenic mice [75]. Furthermore, EGCG has been shown to modulate APP processing, which subsequently leads to the reduction of $\mathrm{A} \beta$ production and cerebral amyloidosis in APP transgenic mice [76]. Potentially, selective inhibition of over-expressed DYRK1A in DS could prevent/reduce some developmental defects, including intellectual deficits, as well as delay/reduce Alzheimer-type pathology and dementia.

\section{Acknowledgments}

The authors are grateful for financial support from the New York State Office of Mental Retardation and Developmental Disabilities and grants from the National Institutes of Health, National Institute of Child Health and Human Development R01 HD043960 (JW), HD038295 (YWH); the National Institute of Aging, AG08051 (JW) and R01 AG027429 (C-XG); the Alzheimer's Association, IIRG-05-13095 (C-XG) and NIRG-08-91126; and the Jerome Lejeune Foundation (YWH). The authors thank Ms. Maureen Marlow for editorial corrections.

\section{Abbreviations}

\begin{tabular}{|c|c|}
\hline AD & Alzheimer disease \\
\hline $\mathbf{A} \boldsymbol{\beta}$ & amyloid- $\beta$ peptide \\
\hline APP & amyloid precursor protein \\
\hline ASF & alternative splicing factor \\
\hline CDK5 & cyclin-dependent kinase 5 \\
\hline DS & Down syndrome \\
\hline DYRK1A & dual-specificity tyrosine phosphorylation-regulated kinase $1 \mathrm{~A}$ \\
\hline E10 & exon 10 \\
\hline ERK1/2 & extracellular signal-regulated kinases $1 / 2$ \\
\hline GSK-3 $\beta$ & glycogen synthase kinase $3 \beta$ \\
\hline GVD & granulovacuolar degeneration \\
\hline JNK & c-Jun N-terminal kinase \\
\hline $\mathbf{L B}$ & Lewy bodies \\
\hline$M n b$ & Minibrain gene \\
\hline NFTs & neurofibrillary tangles \\
\hline SEPT4 & Septin 4 \\
\hline
\end{tabular}

\section{References}

1. Tejedor F, Zhu XR, Kaltenbach E, Ackermann A, Baumann A, Canal I, Heisenberg M, Fischbach KF, Pongs O. Minibrain: a new protein kinase family involved in postembryonic neurogenesis in Drosophila. Neuron 1995;14:287-301. [PubMed: 7857639]

2. Kentrup H, Becker W, Heukelbach J, Wilmes A, Schurmann A, Huppertz C, Kainulainen H, Joost H-G. Dyrk, a dual specificity protein kinase with unique structural features whose activity is 
dependent on tyrosine residues between subdomains VII and VIII. J Biol Chem 1996;271:34883495. [PubMed: 8631952]

3. Song W-J, Sternberg LR, Kasten-Sportes C, Van Keuren ML, Chung S-H, Slack AC, Miller DM, Glover TW, Chiang P-W, Lou L, Kurnit DM. Isolation of human and murine homologues of the Drosophila minibrain gene: human homolog maps to 21q22.2 in the Down syndrome "critical region". Genomics 1996;38:331-339. [PubMed: 8975710]

4. Wisniewski KE. Down syndrome children often have brain with maturation delay, retardation of growth, and cortical dysgenesis. Am J Med Genet, Suppl 1990;7:274-281. [PubMed: 2149962]

5. Wegiel J, Wisniewski HM, Dziewiatkowski J, Popovitch ER, Tarnawski M. Differential susceptibility to neurofibrillary pathology among patients with Down syndrome. Dementia 1996;7:135-141. [PubMed: 8740627]

6. Sadowski M, Wisniewski HM, Tarnawski M, Kozlowski P, Lach B, Wegiel J. Neuronal loss in the entorhinal cortex of aged subjects with Down syndrome. Acta Neuropathol 1999;97:156-164. [PubMed: 9928826]

7. Galceran J, de Graaf K, Tejedor FJ, Becker W. The MNB/DYRK1A protein kinase: genetic and biochemical properties. J Neurol Transm Suppl 2003;67:139-148.

8. Becker W. Dyrk1a. UCSD-Nature Molecule Pages. 200810.1038/mp.a000796.01

9. Tejedor FJ, Hämmerle B. MNB/DYRK1A: a multiple regulator of neuronal development. FEBS J. 2010

10. Lepagnol-Bestel A-M, Zvara A, Maussion G, Quignon F, Ngimbous B, Ramoz N, Imbeaud S, Loe-Mie Y, Benihoud K, Agier N, Salin PA, Cardona A, Khung-Savatovsky S, Kallunki P, Delabar J-M, Puskas LG, Delacroix H, Aggerbeck L, Delezoide A-L, Delattre O, et al. DYRK1A interacts with the REST/NRSF-SWI/SNF chromatin remodeling complex to deregulate gene clusters involved in the neuronal phenotypic traits of Down syndrome. Hum Mol Genet 2009;18:1405-1414. [PubMed: 19218269]

11. Wegiel J, Kuchna I, Nowicki K, Frackowiak J, Dowjat K, Silverman WP, Reisberg B, De Leon M, Wisniewski T, Adayev T, Chen-Hwang M-C, Hwang Y-W. Cell type- and brain structure-specific patterns of distribution of minibrain kinase in human brain. Brain Res 2004;1010:69-80. [PubMed: 15126119]

12. Fotaki V, Dierssen M, Alcántara S, Martínez S, Martí E, Casas C, Visa J, Soriano E, Estivill X, Arbonés ML. Dyrk1A haploinsufficiency affects viability and cause developmental delay and abnormal brain morphology in mice. Mol Cell Biol 2002;22:6636-6647. [PubMed: 12192061]

13. Becker W, Sippl W. DYRK1A: Activation, regulation, and inhibition. FEBS J. 2010

14. Dowjat WK, Adayev T, Kuchna I, Nowicki K, Palminiello S, Hwang YW, Wegiel J. Trisomydriven overexpression of DYRK1A kinase in the brain of subjects with Down syndrome. Neurosci Letters 2007;413:77-81.

15. Becker W, Weber Y, Wetzel K, Eirmbter K, Tejedor FJ, Joost HG. Sequence characteristics, subcellular localization, and substrate specificity of DYRK-related kinases, a novel family of dual specificity protein kinases. J Biol Chem 1998;273:25893-25902. [PubMed: 9748265]

16. Kaczmarski W, Barua M, Bolton D, Hwang Y-W, Rabe A, Albertini G, Wegiel J. Subcellular trafficking of dual-specificity tyrosine phosphorylation-regulated kinase $1 \mathrm{~A}$ is associated with its posttranslational modifications. Brain Res. (submitted).

17. Murakami N, Bolton D, Hwang YW. Dyrk1A binds to multiple endocytic proteins required for formation of clathrin-coated vesicles. Biochemistry 2009;48:9297-9305. [PubMed: 19722700]

18. Marti E, Altafaj X, Dierssen M, de la Luna S, Fotaki V, Alvarez M, Perez-Riba M, Ferrer I, Estivill $\mathrm{X}$. Dyrk1A expression pattern supports specific roles of this kinase in the adult central nervous system. Brain Res 2003;964:250-263. [PubMed: 12576186]

19. Ferrer I, Barrachina M, Puig B, Martinez de Lagran M, Marti E, Avila J, Dierssen M. Constitutive Dyrk1A is abnormally expressed in Alzheimer disease, Down syndrome, Pick disease, and related transgenic models. Neurobiol Dis 2005;20:392-400. [PubMed: 16242644]

20. Wegiel J, Dowjat K, Kaczmarski W, Kuchna I, Nowicki K, Frackowiak J, Mazur Kolecka B, Wegiel J, Silverman WP, Reisberg B, de Leon M, Wisniewski T, Gong C-X, Liu F, Adayev T, Chen-Hwang M-C, Hwang Y-W. The role of overexpressed DYRK1A protein in the early onset of 
neurofibrillary degeneration in Down syndrome. Acta Neuropathol 2008;116:391-407. [PubMed: 18696092]

21. Liu F, Liang Z, Wegiel J, Hwang Y-W, Iqbal K, Grundke-Iqubal I, Ramakrishna N, Gong C-X. Over-expression of Mnb/Dyrk1A contributes to neurofibrillary degeneration in Down syndrome. FASEB J 2008;22:3224-3233. [PubMed: 18509201]

22. Shi J, Zhang T, Zhou C, Chohan MO, Gu X, Wegiel J, Zhou J, Hwang Y-W, Iqbal K, GrundkeIqbal I, Gong C-X, Liu F. Increased dosage of Dyrk1A alters alternative splicing factor (ASF)regulated alternative splicing of tau in Down syndrome. J Biol Chem 2008;283:28660-28669. [PubMed: 18658135]

23. Woods YL, Cohen P, Becker W, Jakes R, Goedert M, Wang X, Proud CG. The kinase DYRK phosphorylates protein-synthesis initiation factor elF2B $\varepsilon$ at Ser539 and the microtubule-associated protein tau at Thr212: potential role for DYRK as a glycogen synthase kinase 3-priming kinase. Biochem J 2001;355:609-615. [PubMed: 11311121]

24. Liu F, Li B, Tung E-J, Grundke-Iqubal I, Iqbal K, Gong C-X. Site-specific effects of tau phosphorylation on its microtubule assembly activity and self-aggregation. Eur J Neurosci 2007;26:3429-3436. [PubMed: 18052981]

25. Reeves RH, Irving NG, Moran TH, Wohn A, Kitt C, Sisodia SS, Schmidt C, Bronson RT, Davisson MT. A mouse model for Down syndrome exhibits learning and behaviour deficits. Nat Genet 1995;11:177-184. [PubMed: 7550346]

26. Singh TJ, Zaidi T, Grundke-Iqbal I, Iqbal K. Modulation of GSK-3-catalyzed phosphorylation of microtubule-associated protein tau by non-proline-dependent protein kinases. FEBS Lett 1996;358:4-8. [PubMed: 7821426]

27. Lovestone $\mathrm{S}$, Reynolds $\mathrm{CH}$. The phosphorylation of tau: a critical stage in neurodevelopment and neurodegenerative processes. Neuroscience 1997;78:309-324. [PubMed: 9145789]

28. Hanger DP, Betts JC, Loviny TLF, Blackstock WP, Anderton BH. New phosphorylation sites identified in hyperphosphorylated tau (paired helical filament-tau) from Alzheimer's disease brain using nanoelectospray mass spectrometry. J Neurochem 1998;71:2465-2476. [PubMed: 9832145]

29. Reynolds CH, Betts JC, Blackstock WP, Nebreda AR, Anderton BH. Phosphorylation sites on tau identified by nanoelectrospray mass spectrometry: differences in vitro between the mitogen activated protein kinases ERK2, c-Jun N-terminal kinase and P38, and glycogen synthase kinase-3ß. J Neurochem 2000;74:1587-1595. [PubMed: 10737616]

30. Lee VM-Y, Goedert M, Trojanowski JQ. Neurodegenerative tauopathies. Annu Rev Neurosci 2001;24:1121-1159. [PubMed: 11520930]

31. Gong C-X, Liu F, Grundke-Iqbal I. Post-translational modifications of tau protein in Alzheimer's disease. J Neurol Transm 2005;112:813-838.

32. Trojanowski JQ, Mawal-Dewan M, Schmidt ML, Martin J, Lee VM. Localization of the mitogenactivated protein kinase ERK in Alzheimer's disease neurofibrillary tangles and senile plaque neurites. Brain Res 1993;618:333-337. [PubMed: 8374766]

33. Chin JY, Knowles RB, Schneider A, Drewes D, Mandelkow E-M, Hyman BT. Microtubuleaffinity regulating kinase (MARK) is tightly associated with neurofibrillary tangles in Alzheimer brain: a fluorescence resonance energy transfer study. J Neuropathol Exp Neurol 2000;59:966971. [PubMed: 11089574]

34. Leroy K, Boutajangout A, Authelet M, Woodgett JR, Anderton BA, Brion J-P. The active form of glycogen synthase kinase- $3 \beta$ is associated with granulovacuolar degeneration in neurons in Alzheimer's disease. Acta Neuropathol 2002;103:91-99. [PubMed: 11810173]

35. Yamaguchi H, Ishiguro K, Uchida T, Takashima A, Lemere CA, Imahori K. Preferential labeling of Alzheimer neurofibrillary tangles with antisera for tau protein kinase (TPK) I/glycogen synthase kinase-3 $\beta$ and cyclin-dependent kinase 5, a component of TPK II. Acta Neuropathol 1996;92:232241. [PubMed: 8870824]

36. Liu W-K, Williams RT, Hall FL, Dickson DW, Yen S-H. Detection of a Cdc2-related kinase associated with Alzheimer paired helical filaments. Am J Pathol 1995;146:228-238. [PubMed: 7856730] 
37. Schwab C, DeMaggio AJ, Ghoshal N, Binder LI, Kuret J, McGeer PL. Casein kinase 1 delta is associated with pathological accumulation of tau in several neurodegenerative diseases. Neurobiol Aging 2000;21:503-510. [PubMed: 10924763]

38. Rossi F, Labourier E, Forne T, Divita G, Derancourt J, Riou JF, Antoine E, Cathala G, Brunel C, Tazi J. Specific phosphorylation of SR proteins by mammalian DNA topoisomerase I. Nature 1996;381:80-82. [PubMed: 8609994]

39. Kondo S, Yamamoto N, Murakami T, Okumura M, Mayeda A, Imaizumi K. Tra2 beta, SF2/ASF and SRp30c modulate the function of an exonic splicing enhancer in exon 10 of tau pre-mRNA. Genes Cells 2004;9:121-130. [PubMed: 15009090]

40. D’Souza I, Schellenberg GD. Arginine/Serine-rich protein interaction domain-dependent modulation of a tau exon 10 splicing enhancer. J Biol Chem 2006;281:2460-2469. [PubMed: 16308321]

41. Goedert M, Jakes R. Mutations causing neurodegenerative tauopathies. Biochem Biophy Acta 2005;1739:240-250.

42. Liu F, Gong C-X. Tau exon 10 alternative splicing and tauopathies. Mol Neurodegen 2008;3(8):110.

43. Wegiel J, Kaczmarski W, Barua M, Kuchna I, Nowicki K, Wang K-C, Wegiel J, Ma S-Y, Silverman WP, Reisberg B, Monteiro I, de Leon M, Wisniewski T, Dalton A, Lai F, Hwang Y-W, Adayev T, Liu F, Iqbal K, Grundke-Iqbal I, Gong C-X. The link between DYRK1A overexpression and several-fold enhancement of neurofibrillary degeneration with 3-repeat tau protein in Down syndrome. J Neuropathol Exp Neurol. (Submitted).

44. Ryoo SR, Jeong HK, Radnaabazar C, Too JJ, Cho HJ, Lee HW, Kim IS, Cheon YH, Ahn YS, Chung SH, Song WJ. DYRK1A-mediated hyperphosphorylation of Tau. A functional link between Down syndrome and Alzheimer disease. J Biol Chem 2007;2828:34850-34857. [PubMed: 17906291]

45. Teller JK, Russo C, DeBusk LM, Angelini G, Zaccheo D, Dagna-Bricarelli F, Scartezzini P, Bertolini S, Mann DMA, Tabaton M, Gambetti P. Presence of soluble amyloid s-peptide precedes amyloid plaque formation in Down's syndrome. Nature Med 1996;2:93-95. [PubMed: 8564851]

46. Lemere CA, Blusztajn JK, Yamaguchi H, Wisniewski T, Saido TC, Selkoe DJ. Sequence of deposition of heterogenous amyloid $\beta$-peptides and APO E in Down syndrome: implications for initial events in amyloid plaque formation. Neurobiol Dis 1996;3:16-32. [PubMed: 9173910]

47. Wisniewski HM, Wegiel J, Popovitch ER. Age-associated development of diffuse and thioflavinS-positive plaques in Down syndrome. Dev Brain Dysfunction 1994;7:330-339.

48. Zigman WB, Schupf N, Sersen E, Silverman W. Prevalence of dementia in adults with and without Down syndrome. Am J Ment Retard 1995;100:403-412. [PubMed: 8718994]

49. Holland AJ, Hon J, Huppert FA, Stevens F, Watson P. Population-based study of the prevalence and presentation of dementia in adults with Down's syndrome. Br J Psychol 1998;172:493-498.

50. Aplin AE, Gibb GM, Jacobsen JS, Gallo JM, Anderton BH. In vitro phosphorylation of the cytoplasmic domain of the amyloid precursor protein by glycogen synthase kinase-3beta. $\mathbf{J}$ Neurochem 1996;67:699-707. [PubMed: 8764598]

51. Suzuki T, Oishi M, Marshak DR, Czernik AJ, Nairn AC, Greengard P. Cell cycle-dependent regulation of the phosphorylation and metabolism of the Alzheimer amyloid precursor protein. EMBO J 1994;13:1114-1122. [PubMed: 8131745]

52. Iijima K, Ando K, Takeda S, Satoh Y, Seki T, Itohara S, Greengard P, Kirino Y, Nairn AC, Suzuki T. Neuron-specific phosphorylation of Alzheimer's beta-amyloid precursor protein by cyclin dependent kinase 5. J Neurochem 2000;75:1085-1091. [PubMed: 10936190]

53. Standen CL, Brownlees J, Grierson AJ, Kesavapany S, Lau KF, McLoughlin DM, Miller CC. Phosphorylation of thr(668) in the cytoplasmic domain of the Alzheimer's disease amyloid precursor protein by stress-activated protein kinase $1 \mathrm{~b}$ (Jun N-terminal kinase-3). J Neurochem 2001;76:316-320. [PubMed: 11146006]

54. Ryoo SR, Cho HJ, Le HW, Jeong HK, Radnaabazar C, Kim YS, Kim MJ, Son MY, Seo H, Chung $\mathrm{SH}$, Song WJ. Dual specificity tyrosine (Y)-phosphorylation regulated kinase 1A-mediated phosphorylation of amyloid precursor protein: evidence for a functional link between Down syndrome and Alzheimer's disease. J Neurochem 2008;104:1333-1344. [PubMed: 18005339] 
55. Lee MS, Kao SC, Lemere CA, Xia W, Tseng HC, Zhou Y, Neve R, Ahlijanian MK, Tsai LH. APP processing is regulated by cytoplasmic phosphorylation. J Cell Biol 2003;163:83-95. [PubMed: 14557249]

56. Vingtdeux V, Hamdane M, Gompel M, Bégard S, Drobecq H, Ghestem A, Grosjean ME, Kostanjevecki V, Grognet P, Vanmechelen E, Buée L, Delacourte A, Sergeant N. Phosphorylation of amyloid precursor carboxy-terminal fragments enhances their processing by a gammasecretase-dependent mechanism. Neurobiol Dis 2005;20:625-637. [PubMed: 15936948]

57. Sakono M, Zako T. Amyloid oligomers: formation and toxicity of A $\beta$ oligomers. FEBS J 2010;277:1348-1358. [PubMed: 20148964]

58. Kimura R, Kamino K, Yamamoto M, Nuripa A, Kida T, Kazui H, Hashimoto R, Tanaka T, Kudo T, Yamagata H, Tabara Y, Miki T, Akatsu H, Kosaka K, Funakoshi E, Nishitomi K, Sakaguchi G, Kato A, Hattori H, Uema T, Takeda M. The DYRK1A gene, encoded in chromosome 21 Down syndrome critical region, bridges between beta-amyloid production and tau phosphorylation in Alzheimer disease. Hum Mol Genet 2007;16:15-23. [PubMed: 17135279]

59. Guimera J, Casas C, Estivill X, Pritchard M. Human Minibrain homologue (MNBH/DYRK1): characterization, alternative splicing, differential tissue expression, and overexpression in Down syndrome. Genomics 1999;57:407-418. [PubMed: 10329007]

60. Engidawork E, Lubec G. Molecular changes in fetal Down syndrome brain. J Neurochem 2003;84:895-904. [PubMed: 12603815]

61. Kim EJ, Sung Y, Lee HJ, Rhim H, Hasegawa M, Iwatsubo T, Min do S, Kim J, Paik SR, Chung KC. Dyrk1A phosphorylates alpha-synuclein and enhances intracellular inclusion formation. J Biol Chem 2006;281:33250-33257. [PubMed: 16959772]

62. Lippa CF, Schmidt ML, Lee VM, Trojanowski J. Antibodies to $\alpha$-synuclein detect Lewy bodies in many Down's syndrome brains with Alzheimer's disease. Ann Neurol 1999;45:353-357. [PubMed: 10072050]

63. Sitz JH, Baumgärtel K, Hämmerle B, Papadopoulos C, Hekerman P, Tejedor FJ, Becker W, Lutz B. The Down syndrome candidate dual-specificity tyrosine phosphorylation-regulated kinase $1 \mathrm{~A}$ phosphorylates the neurodegeneration-related septin 4. Neuroscience 2008;157:596-605. [PubMed: 18938227]

64. Ihara M, Tomimoto H, Kitayama H, Morioka Y, Akiguchi I, Shibasaki H, Noda M, Kinoshita M. Association of the cytoskeletal GTP-binding protein Sept4/H5 with cytoplasmic inclusions found in Parkinson's disease and other synucleinopathies. J Biol Chem 2003;278:24095-24102. [PubMed: 12695511]

65. Ihara M, Yamasaki N, Hagivara A, Tanigaki A, Kitano A, Hikawa R, Tomimoto H, Noda M, Takanashi M, Mori H, Hattori N, Miyakawa T, Kinoshita M. Sept4, a component of presynaptic scaffold and Lewy bodies, is required for the suppression of alpha-synuclein neurotoxicity. Neuron 2007;53:519-533. [PubMed: 17296554]

66. Kinoshita A, Kinoshita M, Akiyama H, Tomimoto H, Akiguchi I, Kumar S, Noda M, Kimura J. Identification of septins in neurofibrillary tangles in Alzheimer's disease. Am J Pathol 1998;153:1551-1560. [PubMed: 9811347]

67. Tomlinson BE, Kitchener D. Granulovacuolar degeneration of hippocampal pyramidal cells. J Pathol 1972;106:165-185. [PubMed: 4114032]

68. Ball MJ, Nuttall K. Topography of neurofibrillary tangles and granulovacuoles in hippocampi of patients with Down's syndrome: quantitative comparison with normal ageing and Alzheimer's disease. Neuropathol Appl Neurobiol 1981;7:13-20. [PubMed: 6453301]

69. Price DL, Altschuler RJ, Struble RG, Casanova MF, Cork LC, Murphy DB. Sequestration of tubulin in neurons in Alzheimer's disease. Brain Res 1986;385:305-310. [PubMed: 3096492]

70. Dickson DW, Ksiezak-Reading H, Davies P, Yen SH. A monoclonal antibody that recognizes a phosphorylated epitope in Alzheimer neurofibrillary tangles, neurofilaments and tau proteins immunostains granulovacuolar degeneration. Acta Neuropathol 1987;73:254-258. [PubMed: 2441560]

71. Lowe J, Blanchard A, Morrell K, Lennox G, Reynolds L, Billett M, Landon M, Mayer RJ. Ubiquitin is a common factor in intermediate filament inclusion bodies of diverse type in man, including those of Parkinson's disease, Pick's disease, and Alzheimer's disease, as well as 
Rosenthal fibers in cerebellar astrocytomas, cytoplasmic bodies in muscle, and Mallory bodies in alcoholic liver disease. J Pathol 1988;155:9-15. [PubMed: 2837558]

72. Bain J, McLauchlan H, Elliott M, Cohen P. The specificities of protein kinase inhibitors: an update. Biochem J 2003;371:199-204. [PubMed: 12534346]

73. Bain J, Plater L, Elliott M, Shpiro N, Hastie CJ, McLauchlan H, Klevernic I, Arthur JS, Alessi DR, Cohen P. The selectivity of protein kinase inhibitors: a further update. Biochem J 2007;408:297315. [PubMed: 17850214]

74. Xie W, Ramakrishna N, Wieraszko A, Hwang YW. Promotion of neuronal plasticity by (-)epigallocatechin-3-gallate. Neurochem Res 2008;33:776-783. [PubMed: 17943438]

75. Guedj F, Sebrie C, Rivals I, Ledru A, Paly E, Bizot JC, Smith D, Rubin E, Gillet B, Arbones M, Delabar JM. Green tea polyphenols rescue of brain defects induced by overexpression of DYRK1A. PLoS One 2009;4:e4606. [PubMed: 19242551]

76. Rezai-Zadeh K, Shytle D, Sun N, Mori T, Hou H, Jeanniton D, Ehrhart J, Townsend K, Zeng J, Morgan D, Hardy J, Town T, Tan J. Green tea epigallocatechin-3-gallate (EGCG) modulates amyloid precursor protein cleavage and reduces cerebral amyloidosis in Alzheimer transgenic mice. J Neurosci 2005;25:8807-8814. [PubMed: 16177050] 


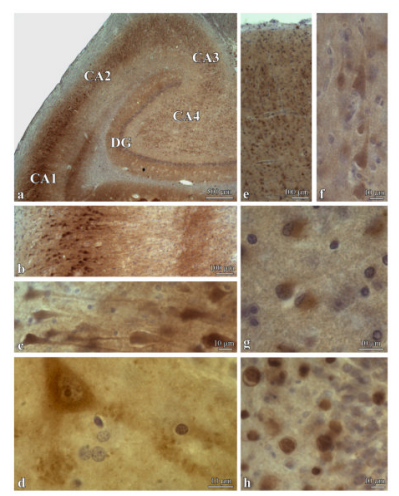

Fig. 1.

DYRK1A distribution in DS. DYRK1A immunolabelling with $\mathrm{mAb} 7 \mathrm{~F} 3$ in the hippocampus of a 56-year-old DS subject illustrates sector- and layer-specific differences in the distribution of DYRK1A in neurons and neuronal processes in CA1-4 and the dentate gyrus (DG) (a). The most intensive reaction is observed in CA1 pyramidal neurons in bodies and apical dendrites (b, c). High magnification of neuron shows immunoreactivity in the nucleus, cytoplasm and synapses in the CA4 sector (d). Immunoreactivity in cortex is weaker than in hippocampus and is more prominent in pyramidal than granule neurons (e, $\mathrm{f}$ ). In DS, regionally astrocytes show strong diffuse cell body immunoreactivity (temporal lobe; g). DYRK1A immunoreactivity in the corpora amylacea in the dentate gyrus $(\mathrm{h})$ reflects DYRK1A contribution to astrocytes and neuronal degeneration. 


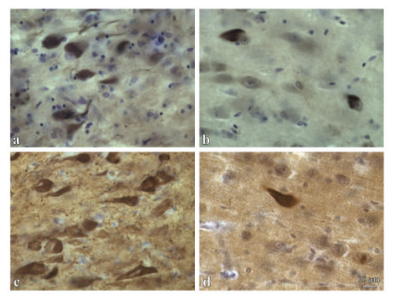

Fig. 2.

Prevalence of 3R tau-positive NFTs in DS. The several-fold more DYRK1A-positive NFTs in DS (a) than in AD (b), and the several-fold more 3R tau-positive NFTs in DS (c) than in $\mathrm{AD}(\mathrm{d})$ are direct evidence of the enhanced contribution of DYRK1A to neurofibrillary degeneration in DS.

The figure illustrates changes in sector CA1 of a 54-year-old DS male (a and c) and an 84year-old male (b and d), both diagnosed with severe AD. 


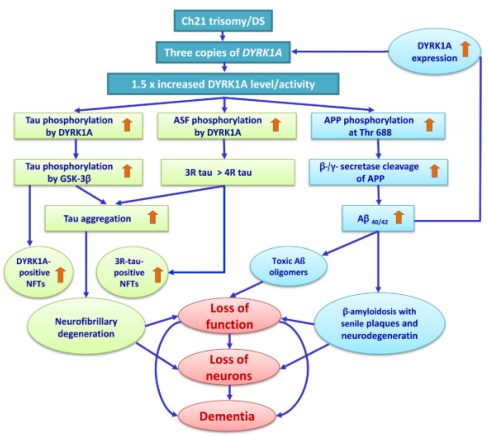

Fig. 3.

Contribution of overexpressed DYRK1A to $\beta$-amyloidosis and neurofibrillary degeneration in DS. Gene-dose elevation of DYRK1A expression associated with trisomy 21 could lead to the activation of two pathways contributing to neurofibrillary degeneration and one contributing to brain $\beta$-amyloidosis. DYRK1A phosphorylates tau at 11 sites, including Thr212; primes tau phosphorylation by GSK-3 $\beta$; promotes tau aggregation into NFTs and the several-fold increase in the number of DYRK1A-positive NFTs. Phosphorylation of ASF by nuclear DYRK1A increases the level of 3R tau, leading to an imbalance in the 3R/ 4R-tau ratio and triggering neurofibrillary degeneration with a several-fold increase of $3 \mathrm{R}$ tau-positive NFTs. Both cytoplasmic and nuclear pathways contribute to neurofibrillary degeneration, loss of neuron function, and neuronal death.

DYRK1A phosphorylates APP at Thr688 and enhances APP amyloidogenic cleavage, resulting in increased level of $A \beta_{40 / 42}$, formation of toxic $A \beta$ oligomers and deposition of fibrillar amyloid in plaques. Brain amyloidosis contributes to loss of neuronal function and possibly also to neuronal loss. Moreover, elevated levels of A $\beta$ may up-regulate DYRK1A expression and enhance the contribution of overexpressed DYRK1A to neurofibrillary degeneration and $\beta$-amyloidosis. 